\title{
Effect of modified graphene and carbon nanotubes on the thermal properties and flammability of elastomeric materials
}

\author{
Przemysław Rybiński $^{1}$ - Rafał Anyszka ${ }^{2}$ Mateusz Imiela ${ }^{2}$ Mariusz Siciński ${ }^{2}$. \\ Tomasz Gozdek ${ }^{2}$
}

Received: 24 March 2016/ Accepted: 5 September 2016/Published online: 20 September 2016

(c) The Author(s) 2016. This article is published with open access at Springerlink.com

\begin{abstract}
The paper presents the test results of the effect of modified graphene and multi-wall carbon nanotubes on the thermal and mechanical properties and flammability of acrylic rubber and styrene-butadiene rubber. The rubbers were cross-linked with the use of organic peroxide. Based on the test results obtained by optic and AFM methods, a relationship between the surface morphology of the nanocomposites obtained was presented. By means of thermal analysis methods (TG, DTG, DTA) and a microcalorimeter, it has been found that the nanofillers used considerably increase the thermal stability and decrease flammability of the nanocomposites. The mechanical properties of the elastomeric materials obtained depend on the type and content of nanofiller.
\end{abstract}

Keywords Modified graphene - MWCNTs - Elastomer · Thermal properties $\cdot$ Mechanical properties $\cdot$ Flammability

\section{Introduction}

Recent years have witnessed a great interest in polymeric materials with special properties, resistance to the action of considerably lowered or increased temperature, flame retardance and showing appropriate mechanical strength. It is the flammability of polymers that is of paramount

Przemysław Rybiński

przemyslaw.rybinski@ujk.kielce.pl

1 Department of Management and Protection Environment, Jan Kochanowski University of Humanities and Sciences in Kielce, Kielce, Poland

2 Institute of Polymer and Dye Technology, Technical University of Łódź, Lodz, Poland importance, which results first of all from health and life protection as well as economic reasons [1,2].

Various methods can be used to protect polymeric materials from fire. It can be cited the graft polymerization consisting in inserting into the polymeric backbone flameretardant monomers or more simply the blending of the matrix with a polymer exhibiting higher thermal resistance properties. The most commonly used approach to making thermally stable or low-flammable materials is the incorporation in the polymer of flame-retardant particles dispersed in the matrix. This method is generally preferred to the others because it is easily compatible with industrial processes and because it offers a good compromise between economical considerations, mechanical, thermal and fire properties.

During the last few decades, a new class of polymeric composites has been extensively investigated using fillers in nanometer size range, preferably less than $100 \mathrm{~nm}$. The advantage of nanofillers is that they are miscible with the polymer matrix exploiting unique synergism between the combined materials. These polymer/nanoparticles mixtures are referred to as nanocomposites [3].

Polymer nanocomposites may contain different nanofillers that strongly influence on their flammability. For example, polymer nanocomposites with organically modified layered silicates constitute important group of nanomaterials. They show improved physical properties at low filler content and are not overly complicated to produce.

In the recent time, importance has been given to carbonbased nanofillers, such as graphite nanoplatelets, carbon nanotubes and graphenes (graphene oxide, reduced graphene oxide and modified graphene).

Carbon nanotubes are divided into single-wall carbon nanotubes (SWCNTs), multi-wall carbon nanotubes (MWCNTs) and double-wall carbon nanotubes that now 
are of rather marginal importance. Most of SWCNTs have a diameter of about $1 \mathrm{~nm}$ and a length of at least 1000 times exceeding their diameter. The extraordinary physical properties of nanotubes result from their exceptionally high shape coefficient that directly influences both the force at break and Young modulus values. For SWCNTs, the value of breaking force ranges from 37 to $100 \mathrm{GPa}$, while the value of Young modulus from $640 \mathrm{GPa}$ to $2 \mathrm{TPa}$. For example, the value of steel breaking force and Young modulus ranges from 200 to $400 \mathrm{GPa}$ and from 10 to $20 \mathrm{GPa}$, respectively $[4,5]$.

Equally good as those of carbon nanotubes are mechanical parameters of graphene. Graphene is a twodimensional allotropic variety of carbon, in which each carbon atom is connected with the next bond with hybridization $s p^{2}$ having a length of $0.141 \mathrm{~nm}$. Its closepacked carbon atoms form a honeycomb crystallographic structure. The thickness of $2 \mathrm{D}$ graphene layer ranges at the average from 1 to $1.6 \mathrm{~nm}[6,7]$.

Owing to its excellent electric properties, graphene more and more frequently displaces metallic conductors in electrical equipment. It is assumed that soon it will replace fragile and chemically unstable tin and indium oxides used in the production of touch screens [8-11].

Graphene as 2D carbon nanofiller with a large specific surface and excellent electric, thermal and mechanical properties is also more and more often used to prepare polymeric nanocomposites [12-14].

However, the preparation of homogeneous polymergraphene composites gives rise to many difficulties. Firstly, the commercial production of polymeric nanocomposites requires a great amount of nanofiller, and secondly a pure graphene is difficult to disperse in polymeric matrix [15-17].

Graphene layers, on account of their large specific surface, show a tendency to aggregate and agglomerate, and even to the recreation of graphite by the interactions of $\pi$ electrons and Van der Waals forces, especially if particular graphene layers are not remote enough from themselves in the polymeric matrix $[6,18]$.

Nowadays, graphene is obtained by the micro-mechanical tearing of graphite, chemical vapor deposition (CVD), arc discharge and epitaxial increase on electrically insulated surfaces such as $\mathrm{SiC}$, development of carbon nanotubes and reduction of graphite oxide [19-22]. From among the above-mentioned methods, the latter allows one to produce graphene in commercial amounts.

An increase in the graphene compatibility in relation to a polymeric matrix can be obtained by its chemical modification.

On account of its aromatic nature, graphene is characterized by a high electronic density, both over and under plane, which causes that the molecular orbitals of organic molecules easily react with the $\pi$ electrons of graphene. This in turn causes that its modification can proceed by electrophile substitution (privileged reactions) as well as by nucleophilic substitution [6].

The method of functionalization of graphene, used on an industrial scale, consists of aminated graphene oxide. The reaction proceeding according to the mechanism of nucleophilic substitution proceeds quickly and with a high yield even at room temperature (Scheme 1) $[6,17]$.

The presence of hydrophilic or hydrophobic functional groups added to the surface of graphene protects it against aggregation in polymeric matrix through creating strong polar interactions as well as steric hindrance.

In recent years, there have been many published reports describing the physical properties of polymeric composites containing carbon nanofillers [23-30]. There is still a lack of systematic studies presenting the impact of this kind of fillers on the thermal properties and flammability of polymeric composites.

In this study, we present the effect of carbon nanotubes and graphene on the thermal properties and flammability of elastomeric nanocomposites.

\section{Materials and methods}

\section{Materials}

The objects of studies were rubbers:

- acrylic rubber (ACR), trade mark Vamac DP from DuPont, Mooney Viscosity, ML $\left(1+4\right.$ at $\left.100{ }^{\circ} \mathrm{C}\right) 22$,

- butadiene-styrene rubber (SBR), trade mark KER 1500 from Synthos, Mooney Viscosity, ML $(1+4$ at $\left.100{ }^{\circ} \mathrm{C}\right) 45-55$.

The rubbers under investigation were cross-linked by means of dicumyl peroxide (DCP) in a quantity of 1 part by mass of $\mathrm{DCP} / 100$ parts of rubber.

The following were used as fillers of elastomeric blends:

- multi-wall carbon nanotubes (MWCNTs), made by Cheap Tubes Inc., with a diameter of $8-15 \mathrm{~nm}$, length of $10-50 \mu \mathrm{m}$ and specific surface above $110 \mathrm{~m}^{2} \mathrm{~g}^{-1}$,

- aminated graphene nanolayers from Cheap Tubes Inc., with a purity of $99 \%$, diameter of $1-2 \mu \mathrm{m}$, thickness below $3 \mathrm{~nm}$ and specific surface over $700 \mathrm{~m}^{2} \mathrm{~g}^{-1}$.

Carbon nanotubes were incorporated into the rubber matrix in quantities of 5,10 and 20 parts by mass, while graphene in amounts of 10 and 20 parts by mass.

For comparison purposes, the rubbers investigated were also filled with graphite in quantities of 10 and 20 parts by mass. 
Scheme 1 Preparation of functionalized graphene sheets from graphite

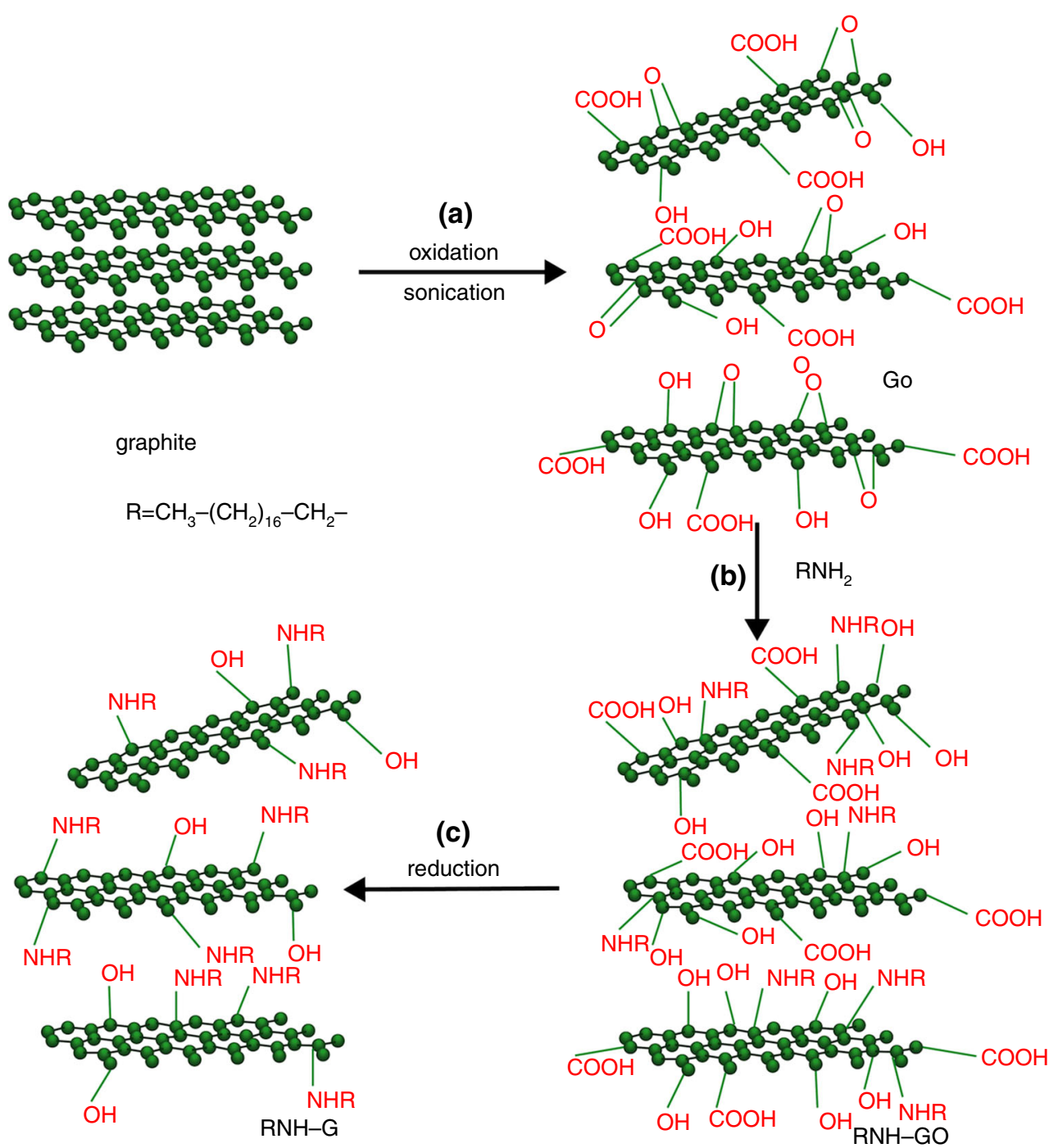

\section{Methods}

Preparation of elastomeric mixtures

Elastomeric blends were prepared at room temperature with the use of a laboratory rolling mill $(D=150 \mathrm{~mm}$ and $L=300 \mathrm{~mm}$ ). The rotational speed of the front roll was $20 \mathrm{rpm}$, friction 1.1 .

\section{Vulcanization of elastomeric blends}

The elastomeric blends were vulcanized in steel molds placed between electrically heated press shelves. The optimal vulcanization time $\left(\tau_{0,9}\right)$ at a temperature of $160{ }^{\circ} \mathrm{C}$ was determined by means of a WG-2 vulcameter according to PN-ISO 3417:1994.
Analysis of filler dispersion in vulcanizates

Optic analysis The analysis of filler dispersion in vulcanizates was performed by means of a DisperTester 3000 microscope according to standard ISO 11345:2006.

The measurement principle consists in recording, by means of a camera with a high definition, the light reflected from the surface of agglomerates present on the surface of the sample cross sections tested. The microscope software determines the size of aggregates within the range $1-10 \mu \mathrm{m}$ (jump every $1 \mu \mathrm{m}$ ) and within the range $10-100 \mu \mathrm{m}$ (jump every $10 \mu \mathrm{m}$ ). The analysis of light reflected from the surface of sample cross sections also provides information about the number of aggregates and agglomerates below $1 \mu \mathrm{m}$ and over $100 \mu \mathrm{m}$. 
AFM analysis AFM (atomic force microscope) measurements were taken by means of Metrology Series 2000, Molecular Imaging (USA) apparatus. Imaging was carried out with the use of a scanning siliceous head with conical shape (dilation angle $<20^{\circ}$ ) and height about 15-20 $\mu \mathrm{m}$ operating in oscillatory mode with a resonance frequency of about $170 \mathrm{kHz}$. Samples for measurements were vulcanized in a steel mold. A glass plate was placed in the mold to obtain a low coarseness of vulcanizate surface. Before placing in the mold, the glass plate surface was rinsed with acetone and dried in air jet to degrease it and remove impurities.

The image analysis was performed by means of the WS $\times$ M program worked out and made available by Horcas et al. [31].

\section{Thermal analysis}

Thermal analysis of fillers:

The thermal properties of the fillers were tested under air within the temperature range of $25-800{ }^{\circ} \mathrm{C}$ by means of a MOM derivatograph (Budapest), using $\mathrm{Al}_{2} \mathrm{O}_{3}$ as a reference substance. Weighed portions were $90 \mathrm{mg}$ each, heating rate was $7.9{ }^{\circ} \mathrm{C} \mathrm{min}-1$, and the sensitivities of thermal curves were as follows: $\mathrm{TG}=100, \mathrm{DTA}=1 / 5$, $\mathrm{DTG}=1 / 30$.

Thermal analysis of nanocomposites:

The thermal properties of the nanocomposites were tested under air and nitrogen gas at temperatures ranging from 25 to $700{ }^{\circ} \mathrm{C}$, with the use of a Jupiter STA 449 F3 thermal analyzer from Netzsch Company. Weighed portions amounted to 5-10 mg. Samples were analyzed with heating rates $2,5,10,15^{\circ} \mathrm{C} \mathrm{min}^{-1}$.

Thermal analysis under nitrogen at -120 to $500{ }^{\circ} \mathrm{C}$ of both the rubber and its cross-linked blends was performed by means of differential scanning calorimetry, using a DSC-204 thermal analyzer from Netzsch Company, and weighed portions from 5 to $7 \mathrm{mg}$ and a heating rate of $10{ }^{\circ} \mathrm{C} \min ^{-1}$.

\section{Determination of activation energy of decomposition investigated composites}

The analysis is based on the Flynn-Wall-Ozawa method. This isoconversional integral method, suggested independently by Flynn and Wall and Ozawa, uses Doyle's approximation of the temperature integral. This method is based on the equation [32-35]:

$\log \beta=\log \frac{A E}{R g(\alpha)}-2.315-\frac{0.457 E}{R T}$ where $\beta$ is the heating rate ${ }^{\circ} \mathrm{C} \min ^{-1} ; A$ the pre-exponential factor; $E$ activation energy of decomposition in $\mathrm{kJ} \mathrm{mol}^{-1}$; $R$ the universal gas constant; $\alpha$ the degree of conversion; $T$ the absolute temperature to reach the conversion, and $g(\alpha)$ the integrated form of kinetic model $f(\alpha)$ conversion function.

$g(\alpha)$ could be expressed by the equation:

$g(\alpha)=\int_{0}^{\alpha} \frac{\mathrm{d} \alpha}{f(\alpha)}$

Thus, at a constant conversion ( $\alpha=$ const.), the plot $\log \beta$ versus $(1 / T)$, obtained from a series of experiments performed at several heating rates, should be a straight line whose slope allows evaluation of the activation energy:

slope $=\frac{\mathrm{d}(\log \beta)}{\mathrm{d}(1 / T)}=0.4567\left(\frac{E}{R}\right)$

To apply this isoconversional method, heating rates of 2,5 , 10 and $15{ }^{\circ} \mathrm{C} \min ^{-1}$ were chosen. In this study, the conversion values of $10,20,30,40,50,60,70,80$ and $90 \%$ have been used, which would give $\alpha$ values $0.1,0.2,0.3$, $0.4,0.5,0.6,0.7,0.8,0.9$, respectively, for the FlynnWall-Ozawa method.

\section{Flammability test}

Flammability tests were carried out with the use of a microcalorimeter from Testing Technology Limited [36].

Pyrolyzer temperature was $750{ }^{\circ} \mathrm{C}$, and that of combustor $900{ }^{\circ} \mathrm{C}$. During the measurements, the following parameters were recorded: ignition temperature $\left(T_{\mathrm{z}}\right)$, maximal heat release rate $\left(\mathrm{HRR}_{\mathrm{MAX}}\right)$, total heat release (THR), heat capacity (HRC) and percent of oxygen consumption (OC) during combustion.

A sample was heated with the rate $1{ }^{\circ} \mathrm{C} \min ^{-1}$ using a linear temperature program, and the volatile decomposition products were carried off from the pyrolyzer chamber by means of inert gas and combined with excess oxygen in a tube oven at the flame temperature to force flameless total combustion (oxidation) of the fuel. Combustion products: $\mathrm{CO}_{2}, \mathrm{H}_{2} \mathrm{O}$ and acidic gases, were removed from the gas stream, and the heat release rate was calculated on the basis of measured intensity of their flow and oxygen concentration after the correction of flow dispersion. The maximal heat released rate, standardized in relation to the initial sample mass and heat ratio, was determined with the material flammability parameter determined with the unit of released heat capacity $\left(\mathrm{J} \mathrm{g}^{-1} \mathrm{~K}^{-1}\right)$ that depends exclusively on the sample chemical composition and is proportional to the material combustion rate during fire. 
Fig. 1 AFM pictures of composites of ACR rubber containing unmodified graphite
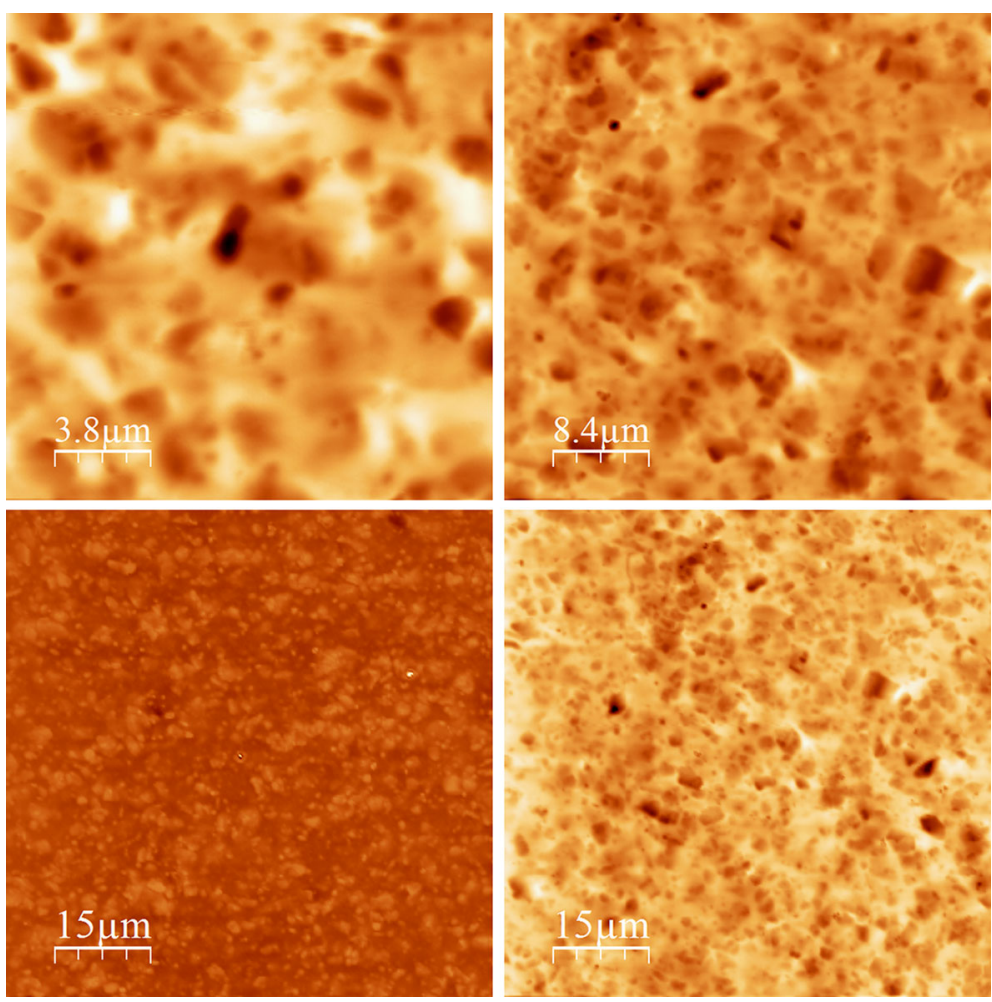

Comparatively, the composites were tested with the use of a cone calorimeter from Fire Testing Technology Limited. Nanocomposites samples with dimensions $(100 \times 100 \pm 1) \mathrm{mm}$ and a thickness of $(20 \pm 0,5) \mathrm{mm}$ were tested in a horizontal position, with a density of heat radiation flux amounting to $35 \mathrm{~kW} \mathrm{~m}^{-2}$.

\section{Mechanical properties}

Tensile strength properties were determined according to the standard PN-ISO 37:1998 by means of a Zwick tensile tester, model 1435, linked to an appropriate PC software. Samples for testing were in the shape of dumbbell with a measurement section width of $4 \mathrm{~mm}$ and thickness $1 \pm 0.001 \mathrm{~mm}$.

\section{Results}

\section{Morphology of surface}

One of the basic difficulties in dispersing filler nanoparticles in the polymeric matrix is the high viscosity and low surface energy. The homogeneous dispersion of both graphene flakes and carbon nanotubes is of essential importance from the point of view of the nanocomposites properties.
Graphene is prepared from graphite by its oxidation to graphene oxide, usually with the use of the extremely effective method of Hummers [37]. The reduction of graphene oxide is carried out by means of chemical, thermal or photochemical processes. One should, however, take into account the fact that the reduction of dispersed graphene oxide in organic solvents without any stabilizers, by means of reverse aggregation of graphene flakes, results in graphite precipitation. Therefore, before the reduction process, grapheme oxide is subjected to processes of non-conventional functionalization or more often to chemical covalent modification. Covalent modification concerns the edges of graphene flakes or their external surfaces and is connected with rehybridization of one or more carbon atoms (hybridization change from $s p^{2}$ to $s p^{3}$ ). The covalent modification of graphene can be performed by means of the following reactions: nucleophilic substitution, electrophilic addition or condensation or addition.

In industrial practice, most frequently, the nucleophilic substitution process is used where epoxy groups added to graphene oxide are used. The free electron pair on nitrogen atom of appropriate amine reagent attacks the epoxy groups added to graphene oxide. Contrary to other processes, the reaction mentioned above proceeds very easily at room temperature (Scheme 1). 
As shown by the results obtained by AFM method, the presence of amine groups and a low number of hydroxyl groups added to the surface of graphene flakes decisively improve their dispersion in polar acrylic rubber and, consequently, prevent their resultant aggregation to graphite (Figs. 1, 2).

The analysis of filler dispersion in acrylic rubber with the use of a light microscope confirms that an average size of aggregates in the matrix of the rubber tested practically does not exceed $10 \mu \mathrm{m}$ (Fig. 3). Similar relations were obtained for SBR.

Compared to aminated graphene, unmodified graphite decisively more difficult disperses in the ACR rubber matrix. Unmodified graphite makes considerable greater aggregates in relation of modified graphene in ACR matrix (Figs. 1, 2, 3).

It should be also taken into account that the amination of graphene to considerably less extent reduces its susceptibility to aggregation in the matrix of nonpolar SBR than in the matrix of ACR (Fig. 4).

Based on the AFM pictures obtained, one can also conclude that MWCNTs are also decisively more effectively dispersed in ACR (Fig. 5) than in SBR (Fig. 6).

From the source literature it follows that in the case of flexible polymer chains with bulky and aromatic side groups e.g. SBR the interactions of the $\pi-\pi$ polymernanofiller type result in an intensive wrapping of CNTs around the polymeric chain, which facilitates the aggregation of filler.

In the case of polymers with a rigid chain, e.g., those possessing aliphatic side substituents (ACR), interactions of this type are of no greater significance [38].

\section{Thermal properties of nanocomposites}

The thermal analysis under air of the carbon nanofillers shows that the beginning of thermal decomposition of

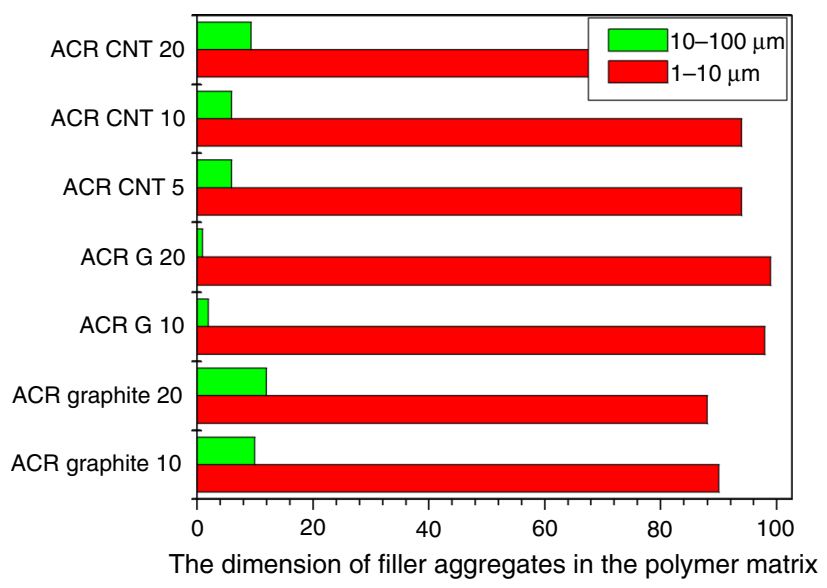

Fig. 3 Optic analysis of composites and nanocomposites of ACR rubber
Fig. 2 AFM pictures of nanocomposites of ACR rubber containing functionalized graphene
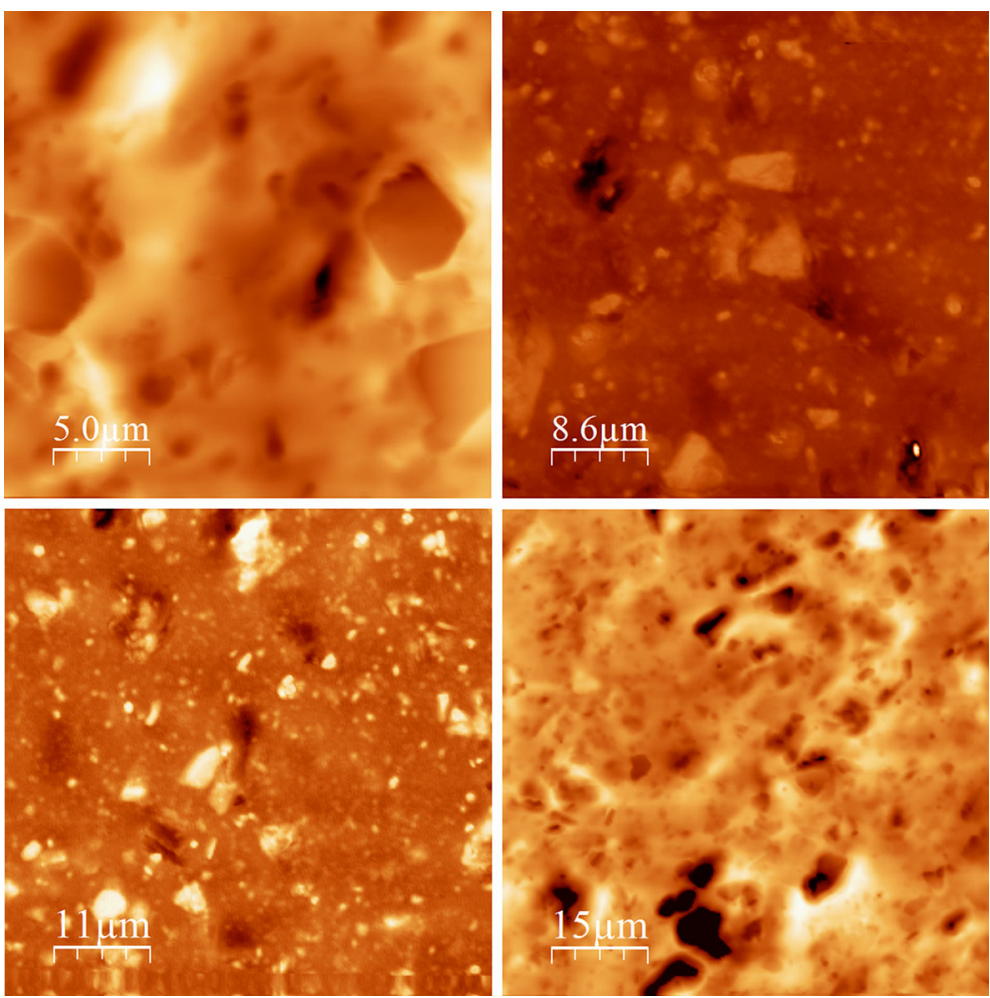
Fig. 4 a, b AFM pictures of nanocomposites of SBR rubber containing functionalized graphene
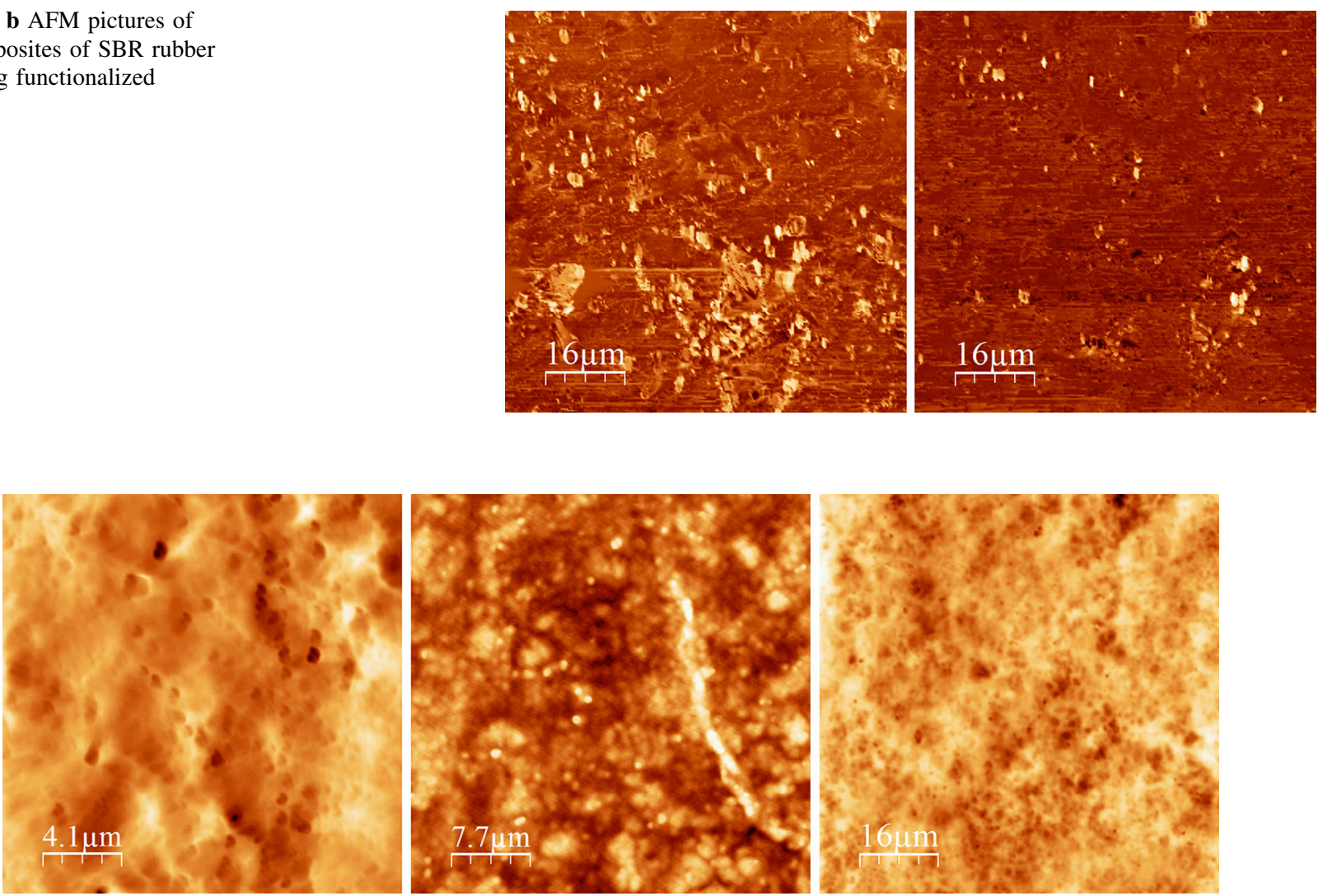

Fig. 5 AFM pictures of nanocomposites of ACR rubber containing CNTs
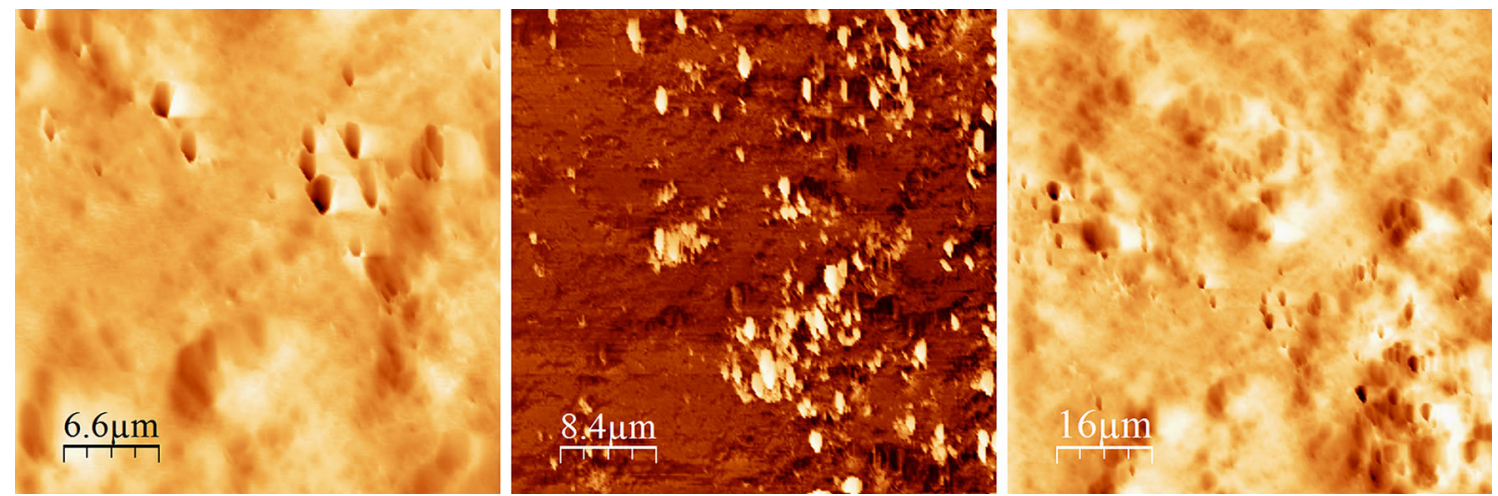

Fig. 6 AFM pictures of nanocomposites of SBR rubber containing CNTs

graphene occurs at $T=200{ }^{\circ} \mathrm{C}$ (Fig. 7), while that of MWCNTs at $T=250^{\circ} \mathrm{C}$ (Fig. 8). A low mass loss of graphene at $\Delta T=200-500{ }^{\circ} \mathrm{C}$ and that of CNTs at $\Delta T=250-450{ }^{\circ} \mathrm{C}$ are connected with the combustion of carbon adsorbed on the nanofiller surface, release of chemically combined water and desorption of low molecular products, i.e., chemically active atoms of oxygen, sulfur and nitrogen. The thermal decomposition of graphene and carbon nanotubes caused by their combustion begins at 590 and $470{ }^{\circ} \mathrm{C}$, respectively, thus beyond the thermal decomposition area of most elastomers. Both graphene and carbon nanotubes are completely burned as confirmed by the exothermal peak recorded in the DTA curve at $T=720{ }^{\circ} \mathrm{C}$ for graphene and at $T=570{ }^{\circ} \mathrm{C}$ for CNTs (Figs. 7, 8).

The addition of fillers does not change the character of thermal processes of the cross-linked ACR and SBR, but it causes a distinct increase in its thermal stability determined by parameters $T_{5}$ and $T_{50}$ (Table 1).

In the case of nanocomposites of acrylic rubber containing graphene, ACR G20, parameter $T_{5}$ increased by about $70{ }^{\circ} \mathrm{C}$ in relation to the unfilled vulcanizate, ACR 
DCP. In the case of nanocomposite of SBR G20, the increase in parameter $T_{5}$ amounts approximately to $100{ }^{\circ} \mathrm{C}$ in relation to unfilled vulcanizate, SBR DCP. A considerable increase in parameter $T_{5}$ is also recorded for nanocomposites ACR and SBR containing carbon nanotubes.

Under the influence of the nanofillers used, the temperature of the maximal rate of nanocomposite decomposition $\left(T_{\text {RMAX }}\right)$ is shifted toward higher temperatures.

A very important parameter of thermal stability of elastomeric material, from the point of view of their flammability, is the thermal decomposition rate, $\mathrm{d} m / \mathrm{d} t$.

Regardless of the chemical structure of macromolecule, the carbon nanofillers used cause a considerable reduction in the thermal decomposition rate, $\mathrm{d} m / \mathrm{d} t$, of the nanocomposites under investigation. It results from the mechanism of mutual elastomer-filler interaction. This mechanism is very complex and has not been yet adequately explained [39].

A considerable reduction in the thermal decomposition rate of the nanocomposites tested in relation to unfilled vulcanizates, ACRDCP and SBRDCP, is due to the decreased segmental mobility of polymeric chains around the particles of nanofiller, which reduces the amplitude of thermal vibration and consequently the processes of thermal degradation and destruction of nanocomposites (Table 2).

Definitely lower values of parameter $\mathrm{d} m / \mathrm{d} t$ of vulcanizates filled with graphene compared to those of the

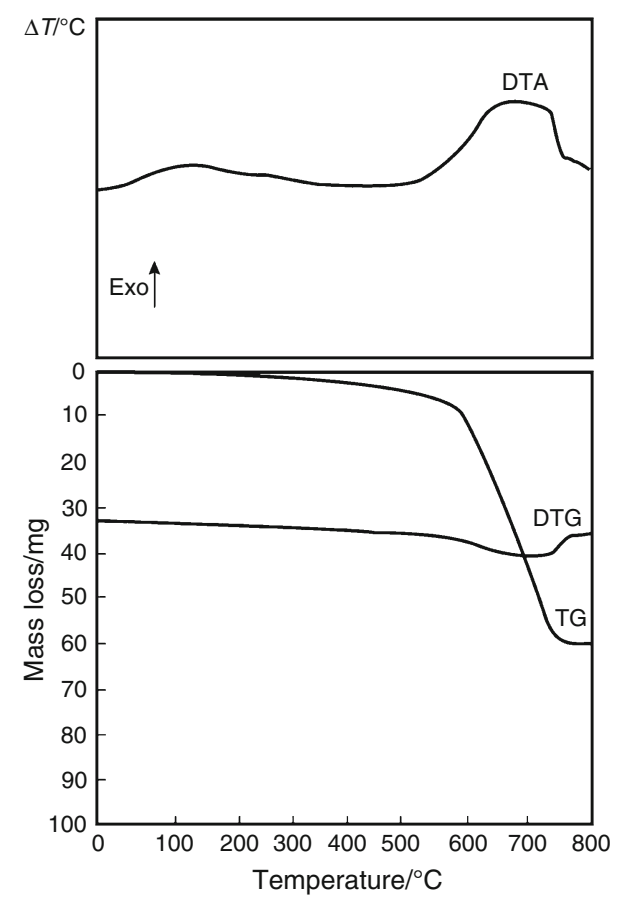

Fig. 7 Thermal curves of functionalized graphene

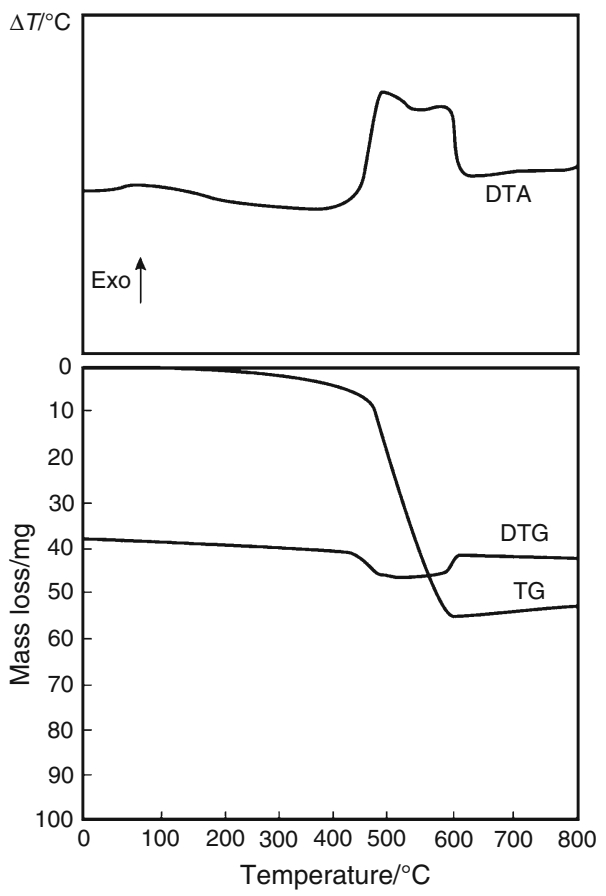

Fig. 8 Thermal curves of CNTs

vulcanizates filled with carbon nanotubes are connected with the decisively higher specific surface of graphene flakes in relation to that of CNTs (Table 1).

Graphene and carbon nanotubes, on account of their honeycomb structure composed of condensed aromatic rings, are perfect scavengers of free radicals. Nowadays, it is assumed that aromatic rings constitute a reactive spot for trapping free macro-radicals formed by thermo-oxidative processes of thermal degradation and destruction of elastomers [40] (Table 2).

An increase in the activation energy of destruction and decrease in parameter $\mathrm{d} m / \mathrm{d} t$ of elastomeric nanocomposites in relation to unfilled vulcanizates indicate that both graphene and CNTs inhibit free radical reactions, increasing at the same time the probability of the recombination of primary macro-radicals through the prolongation of their dwell time in the cage (Tables 1, 2; Figs. 9a, b, 10a, b).

One of the basic parameters of the thermal stability of elastomers and elastomeric materials is the residue after their thermal decomposition $(P w)$. It exerts a significant influence on the flammability of nanocomposites. An increase in this parameter causes that the amount of flammable and nonflammable products of destruction passing to flame is lower. The presence of both graphene and CNTs in ACR as well as SBR nanocomposites distinctly increases the value of parameter $P w$ (Table 1).

An extremely significant parameter of thermal stability from the point of view of fire hazard or flammability under conditions of developed fire of the nanocomposites tested 
Table 1 Thermal properties of nanocomposites

\begin{tabular}{llllllccc}
\hline Sample & $T_{5} /{ }^{\circ} \mathrm{C}$ & $T_{50} /{ }^{\circ} \mathrm{C}$ & $T_{\mathrm{R}} /{ }^{\circ} \mathrm{C}$ & $T_{\mathrm{RMAX}} /{ }^{\circ} \mathrm{C}$ & $\mathrm{d} m / \mathrm{d} t / \% \mathrm{~min}^{-1}$ & $P w / \%$ & $\Delta T_{\mathrm{S}}{ }^{\circ} \mathrm{C}$ & $P_{650} / \%$ \\
\hline ACR DCP & 313 & 429 & 385 & 423 & 13.7 & 18.3 & $485-560$ \\
ACR G10 & 373 & 445 & 372 & 428 & 9.18 & 34.3 & $487-552$ \\
ACR G20 & 381 & 465 & 381 & 449 & 9.50 & 40.4 & $495-565$ \\
ACR CNT5 & 362 & 450 & 380 & 450 & 13.2 & 31.3 \\
ACR CNT10 & 365 & 448 & 390 & 446 & 11.9 & 20.4 & $485-560$ \\
ACR CNT20 & 352 & 448 & 390 & 442 & 9.86 & 27.7 & $495-555$ \\
SBR DCP & 304 & 445 & 413 & 446 & 22.5 & 33.9 & $485-525$ \\
SBR G10 & 400 & 456 & 410 & 452 & 15.5 & 17.1 & $495-595$ \\
SBR G20 & 404 & 455 & 411 & 450 & 12.7 & 30.4 & $495-585$ \\
SBR CNT5 & 392 & 455 & 415 & 453 & 15.6 & 27.1 & $495-580$ \\
SBR CNT10 & 317 & 456 & 415 & 463 & 11.7 & 13.5 \\
SBR CNT20 & 330 & 460 & 410 & 461 & 12.4 & 21.9 & $495-550$ \\
\hline
\end{tabular}

$T_{5} ; T_{50}$-temperatures of sample 5 and $50 \%$ mass loss, respectively; $T_{\mathrm{R}}$-temperature of thermal decomposition; $T_{\mathrm{RMAX}}$-temperature of maximum rate of thermal decomposition of nanocomposites, $\mathrm{d} m / \mathrm{d} t$-maximum rate of thermal decomposition of nanocomposites; $P w-$ residue after the thermal decomposition of nanocomposites; $\Delta T_{\mathrm{S}}$-temperature range of residue burning after the thermal decomposition of nanocomposites; $P_{650}$-residue after heating to $650{ }^{\circ} \mathrm{C}$

Table 2 Values of energy activation destruction of nanocomposites

\begin{tabular}{ll}
\hline Sample & Average $E_{\mathrm{a}} / \mathrm{kJ} \mathrm{mol}^{-1}$ \\
\hline ACR DCP & $129.5 \pm 1.0$ \\
ACR G20 & $209.6 \pm 1.0$ \\
ACR CNT20 & $187.5 \pm 1.0$ \\
SBR DCP & $191.1 \pm 1.5$ \\
SBR G20 & $210.5 \pm 1.5$ \\
SBR CNT20 & $197.2 \pm 1.5$ \\
\hline
\end{tabular}

is parameter $P_{650}$. Regardless of the macromolecule structure, the value of this parameter for nanocomposites filled with graphene is almost ten times higher than that for unfilled vulcanizates. This allows one to state that at this temperature, the boundary layer formed previously still fulfills its role. In the case of nanocomposites containing MWCNTs, parameter $P_{650}$ assumes low values, which indicates a complete combustion of the residue after thermal decomposition at $\Delta T=550-620^{\circ} \mathrm{C}$ (Table 1; Fig. 11).

The thermal analysis of composites and nanocomposites was also performed in the atmosphere of nitrogen. From the DSC curves of the vulcanizates investigated, it follows that regardless of the macromolecule structure the addition of modified graphene or CNTs increases the glass transition temperature, $T_{\mathrm{g}}$, of cross-linked rubbers, which is due to the nanofiller-rubber interaction (Table 3).

\section{Flammability of nanocomposites}

The increase in the thermal stability of nanocomposites under the influence of incorporated nanoadditives is accompanied by the reduction in their flammability. From the comparative analysis of the results obtained by calorimetry, it follows that the flammability of nanocomposites of both ACR and SBR rubber is definitely lower than that of unfilled elastomers, as confirmed by parameters HRR $_{\text {MAX }}$, THR or HRC (Table 4).

In the case of flammability of elastomeric nanocomposites containing carbon nanofillers, the formation of a homogeneous, isolating boundary layer without visible cracks and crevices has an essential influence on the reduction in their flammability.

The isolating properties of boundary layer directly depend on the type of polymer, nanofiller quantity, as well as the degree of its dispersion in the polymeric matrix. Too low quantity of nanofiller, as well as its non-homogeneous distribution in the polymeric matrix causes that during the thermal decomposition of nanocomposite, the destruction products with a relatively low viscosity, formed in its mass, easily get onto the surface of sample by convection. Under the influence of high temperature of the boundary layer, liquid destruction products form quickly growing blisters that moving apart nanofiller particles, lead to the formation of the so-called nanofiller islets that do not provide a sufficient protection against the external heat source (Fig. 12c) [41].

The incorporation of graphene or CNTs in opposite to graphite, with a specified critical concentration into rubbers, as well as their homogeneous distribution in the elastomeric matrix, results in the formation of an internal 3D filler network by means of mutual filler-filler interactions. This network is responsible for both the increase in the viscosity of liquid destruction product and the reduction in the rate of their diffusion onto surface, which results in the formation of small blisters that do not destructively 


\section{(a)}

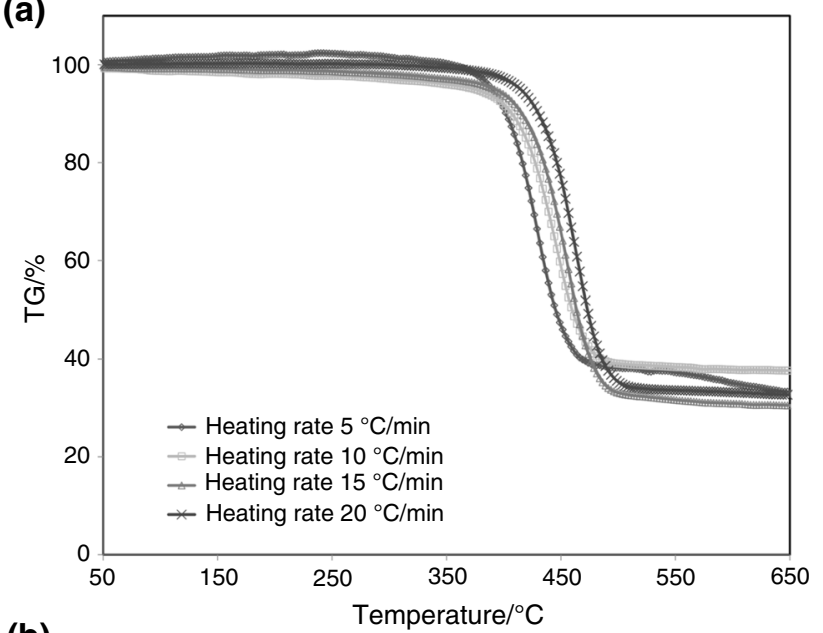

(b)

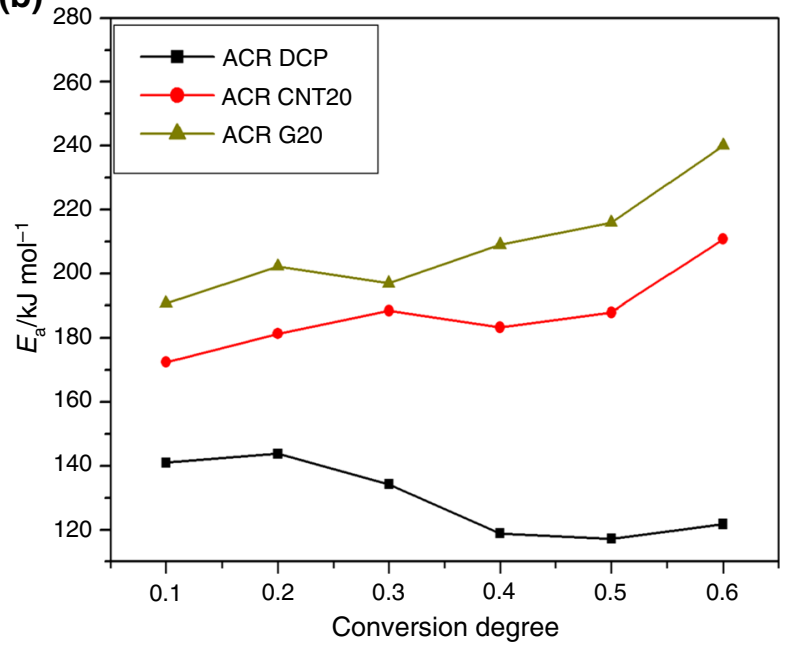

Fig. 9 a Thermal curves of ACRDCP vulcanizates; b relation of value of $E_{\text {a }}$ parameter of ACR composites from the degree of its thermal decomposition

influence the isolating character of the boundary layer being formed during the combustion of nanocomposite.

Graphene and MWCNTs are characterized by a high value of the heat conductivity parameter amounting to from $4.84 \times 10^{3}$ to $5.30 \times 10^{3} \mathrm{~W} \mathrm{~m}^{-1} \mathrm{~K}^{-1} \quad$ [42] and $2 \times 10^{3} \mathrm{~W} \mathrm{~m}^{-1} \mathrm{~K}^{-1}$ [43], respectively. From the review of source literature, it follows that the incorporation of carbon nanofillers, especially graphene into the polymeric matrix, distinctly increases the value of heat conductivity of nanocomposites, which facilitates the reduction in their flammability. The heat reaching the sample surface is transferred to its interior, which decreases the temperature of the sample surface, resulting in a reduction in the efficiency of thermo-oxidative processes, quantity of gases and liquid products of thermal decomposition, and consequently the retardation of ignition [44].

The isolating character of the boundary layer formed is confirmed not only by the value of parameter HRRmax
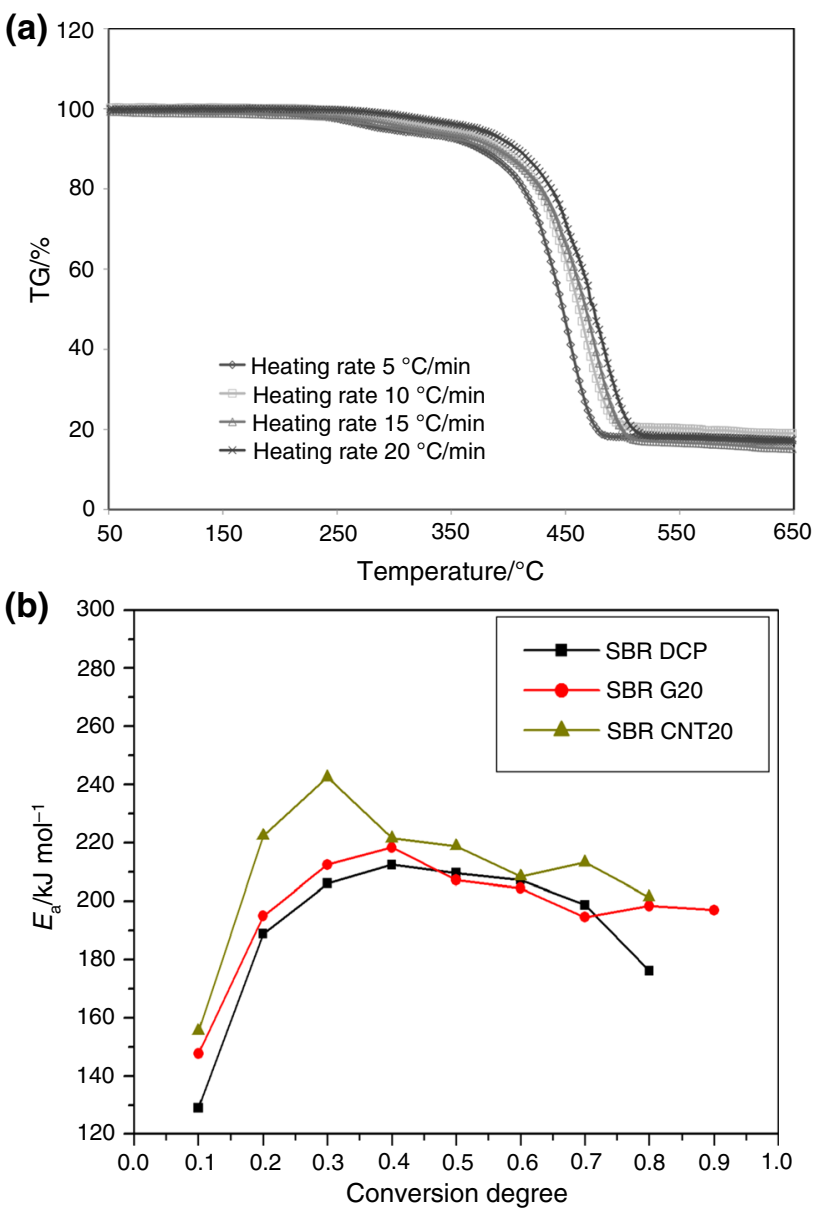

Fig. 10 a Thermal curves of SBRDCP vulcanizates; b relation of value of $E_{\mathrm{a}}$ parameter of SBR composites from the degree of its thermal decomposition

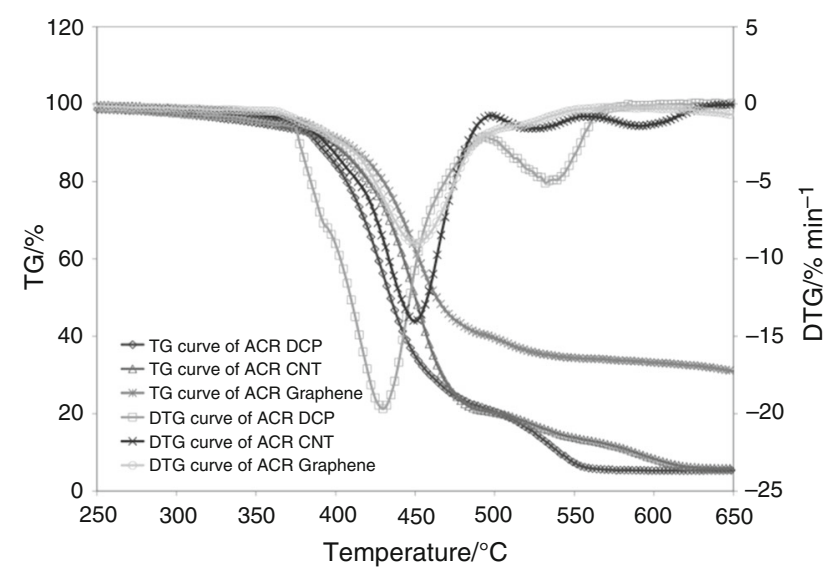

Fig. 11 Thermal curves of nanocomposites of ACR rubber

(maximum heat release rate) decreasing under the influence of nanofillers (Figs. 13, 15), but also by the parameter of oxygen consumption (OC) (Figs. 14, 16).

As follows from the test results obtained, the lowest values of parameters HRRmax and OC are shown by 
Table 3 DSC results (nitrogen atmosphere) of nanocomposites of ACR and SBR rubbers

\begin{tabular}{lll}
\hline Sample & $T_{\mathrm{g}} /{ }^{\circ} \mathrm{C}$ cooling & $T_{\mathrm{g}} /{ }^{\circ} \mathrm{C}$ heating \\
\hline ACRDCP & -45.3 & -40.7 \\
ACR G20 & -27.4 & -22.7 \\
ACR CNT20 & -21.5 & -21.5 \\
SBRDCP & -50.4 & -42.2 \\
SBR G20 & -45.5 & -39.8 \\
SBR CNT20 & -45.5 & -40.3 \\
\hline
\end{tabular}

nanocomposites of ACR and SBR containing graphene in a quantity of 20 parts by mass. Undoubtedly, a great effect on the isolating character of the boundary layer is also exerted by the large specific surface of graphene exceeding $700 \mathrm{~m}^{2} \mathrm{~g}^{-1}$, which causes that graphene also fulfills the function of an absorbing agent of the gaseous products of elastomer thermal decomposition passing to the combustion zone.

\section{Mechanical properties}

From the point of view of the functional properties of elastomeric materials, their mechanical properties play an

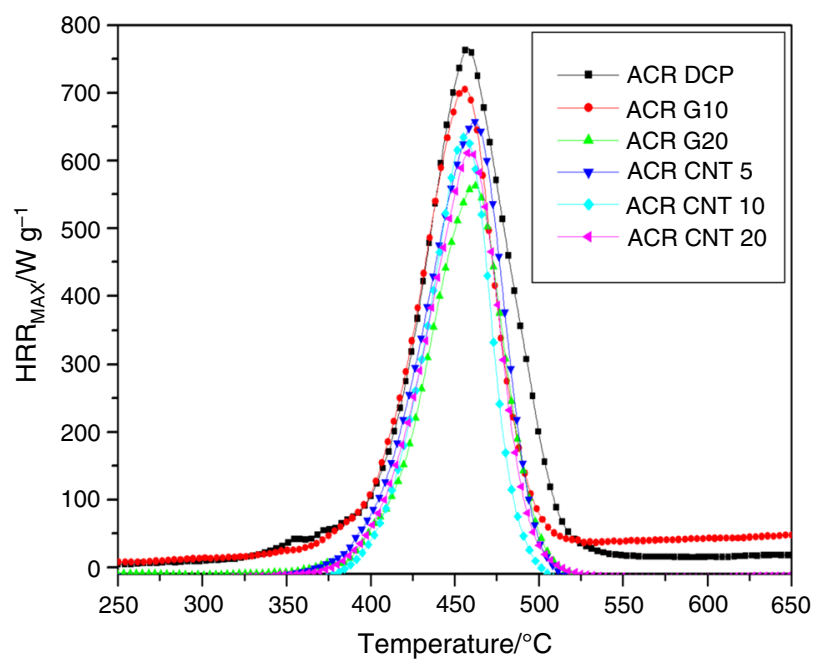

Fig. 13 HRR curves of nanocomposites of ACR rubber

important part. The properties of elastomeric composites as structural materials depend on the physicochemical parameters of their components, but first of all on the size of contact between the continuous phase of polymer and the dispersed phase of filler as well as the character of

Table 4 Flammability of nanocomposites of ACR and SBR rubbers

\begin{tabular}{|c|c|c|c|c|c|}
\hline Sample & $H R R_{\mathrm{MAX}} / \mathrm{W} \mathrm{g}^{-1}$ & $T H R R_{\mathrm{MAX}} /{ }^{\circ} \mathrm{C}$ & $T H R / \mathrm{kJ} \mathrm{g}^{-1}$ & $H R C / \mathrm{J} \mathrm{g}^{-1} \mathrm{~K}^{-1}$ & $\mathrm{OC} / \%$ \\
\hline ACR DCP & 765.6 & 457 & 51.2 & 764 & 53.5 \\
\hline ACR G10 & 705.5 & 454 & 33.8 & 652 & 35.8 \\
\hline ACR G20 & 560.7 & 642 & 28.3 & 556 & 30.2 \\
\hline ACR CNT5 & 657.6 & 462 & 34.9 & 654 & 37.4 \\
\hline ACR CNT10 & 635.1 & 459 & 29.7 & 604 & 38.0 \\
\hline ACR CNT20 & 613.5 & 456 & 29.4 & 639 & 31.5 \\
\hline SBR DCP & 838.4 & 476 & 65.6 & 817 & 74.3 \\
\hline SBR G10 & 677.1 & 473 & 57.5 & 677 & 41.2 \\
\hline SBR G20 & 620 & 470 & 52.6 & 609 & 35.0 \\
\hline SBR CNT5 & 806 & 467 & 59.6 & 787 & 46.1 \\
\hline SBR CNT10 & 760 & 471 & 59.3 & 741 & 42.1 \\
\hline SBR CNT20 & 673.1 & 465 & 49.9 & 665 & 35.4 \\
\hline
\end{tabular}

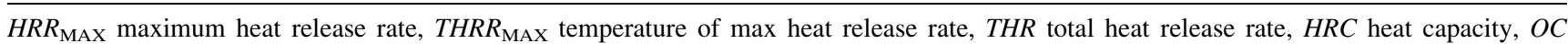
oxygen consumption

(a)

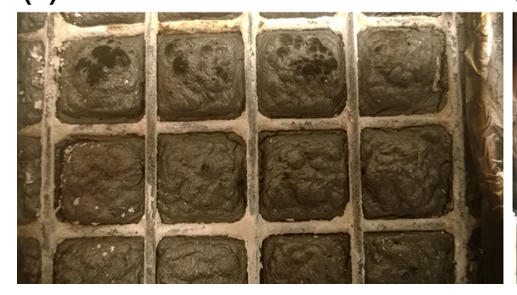

(b)

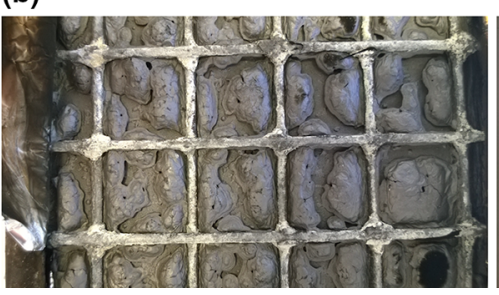

(c)

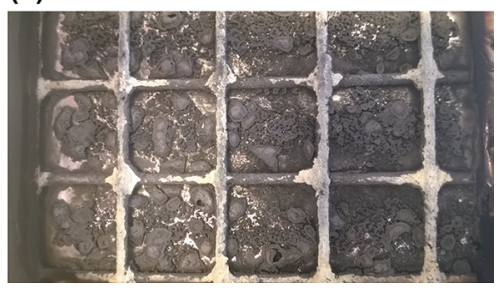

Fig. 12 Photographs of residues from combustion (cone calorimeter). a ACR G20; b ACR CNT20; c ACR graphite 20 


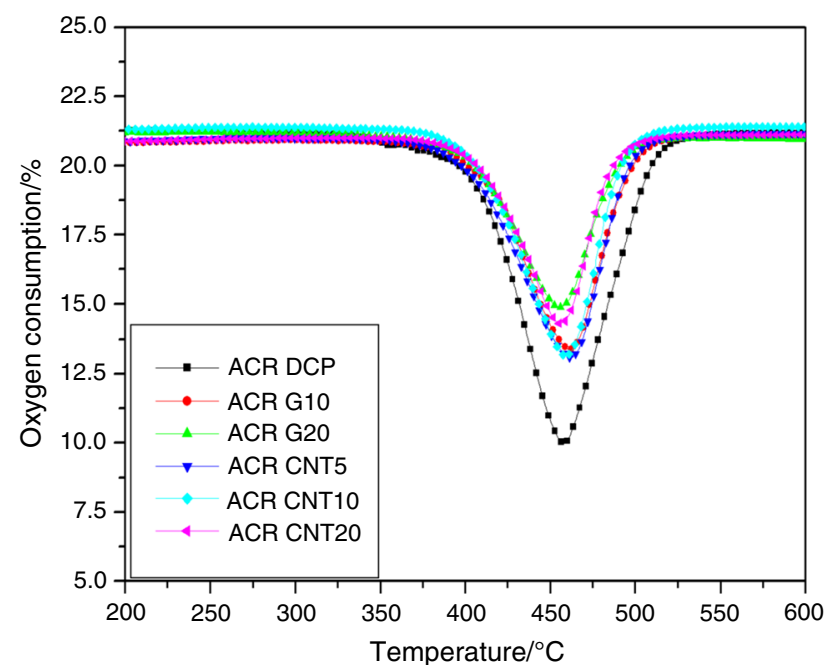

Fig. 14 Oxygen consumption during combustion of investigated nanocomposites of ACR rubber

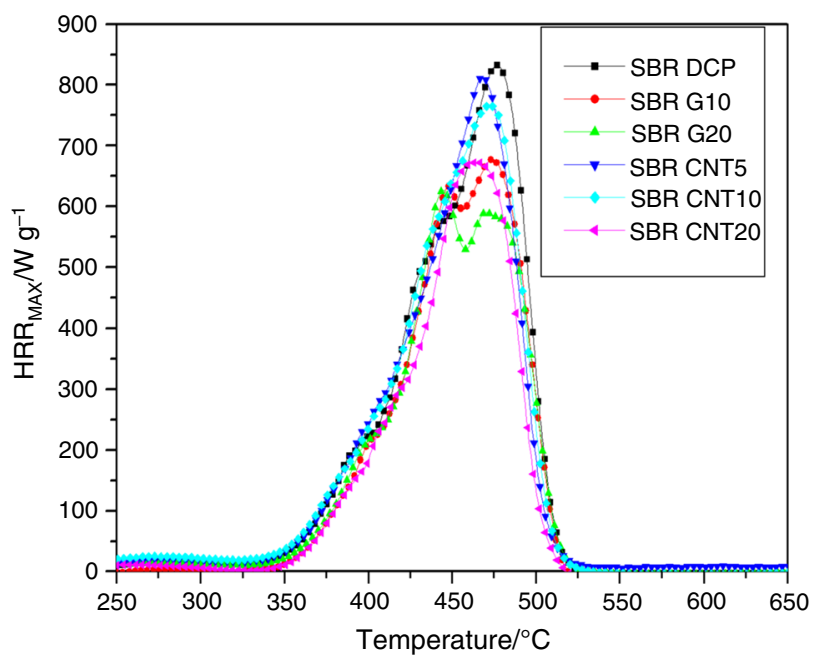

Fig. 15 HRR curves of nanocomposites of SBR rubber

interfacial interactions. The mechanical properties of unfilled vulcanizates of ACR and SBR and their nanocomposites are listed in Table 5. Based on the test results obtained, it may be concluded that graphene homogeneously dispersed in the polymeric matrix considerably increases the value of the breaking force of the nanocomposite. The value of the breaking force of ACR G20 nanocomposite is higher by $217 \%$ than that of unfilled vulcanizate, ACR DCP (Table 5). Also the nanocomposites of SBR G20 are characterized by the breaking force that is higher by more than $300 \%$ compared to that of unfilled vulcanizate of SBR DCP. The incorporation of carbon nanotubes to the matrix of the nanocomposites obtained also considerably improves their

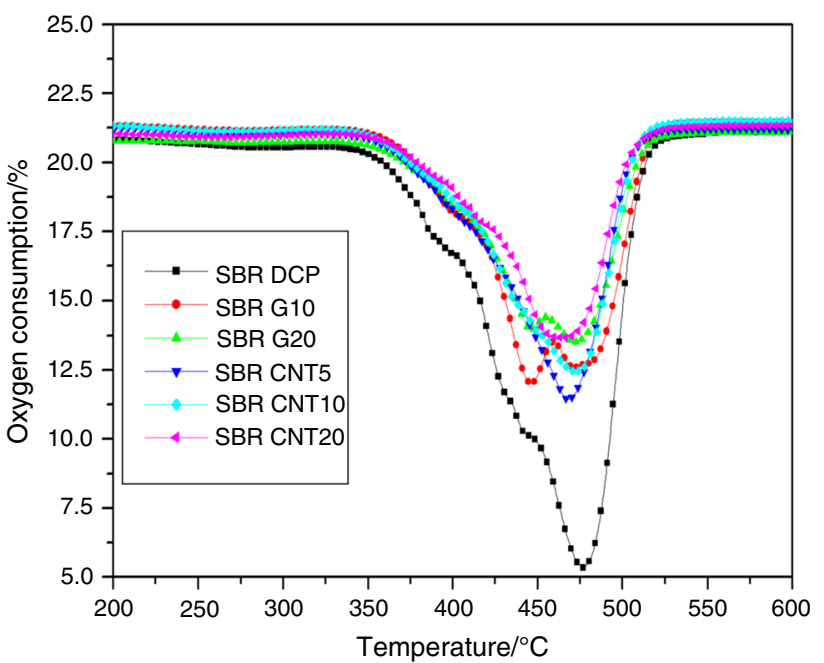

Fig. 16 Oxygen consumption during combustion of investigated nanocomposites of SBR rubber

Table 5 Mechanical properties of nanocomposites of ACR and SBR rubbers

\begin{tabular}{|c|c|c|c|c|c|}
\hline \multirow[t]{2}{*}{ Sample } & \multicolumn{3}{|c|}{$S_{\mathrm{E}} / \mathrm{MPa}$} & \multirow[t]{2}{*}{$T S_{\mathrm{b}} / \mathrm{MPa}$} & \multirow[t]{2}{*}{$E_{\mathrm{b}} / \%$} \\
\hline & $100 \%$ & $200 \%$ & $300 \%$ & & \\
\hline ACR DCP & 0.445 & 0.541 & 0.633 & 2.49 & 841.4 \\
\hline ACR G10 & 0.912 & 1.47 & 2.18 & 7.63 & 1018.8 \\
\hline ACR G20 & 2.21 & 4.21 & 5.62 & 7.91 & 833.9 \\
\hline ACR CNT5 & 1.04 & 1.36 & 1.69 & 5.40 & 1048.6 \\
\hline ACR CNT10 & 2.48 & 3.64 & 4.59 & 7.58 & 849.5 \\
\hline ACR CNT20 & 5.69 & 7.20 & 7.47 & 7.54 & 278.3 \\
\hline SBR DCP & 1.29 & - & - & 1.40 & 107.9 \\
\hline SBR G10 & 1.74 & 3.11 & - & 3.30 & 189.9 \\
\hline SBR G20 & 2.62 & 5.10 & - & 5.65 & 231.0 \\
\hline SBR CNT5 & 1.58 & 2.95 & - & 3.04 & 198.4 \\
\hline SBR CNT10 & 1.77 & 3.22 & - & 3.92 & 235.7 \\
\hline SBR CNT20 & 2.55 & 4.50 & 7.14 & 7.10 & 297.5 \\
\hline
\end{tabular}

$\mathrm{TS}_{\mathrm{b}}$ - tension strength, $E_{\mathrm{b}}$ - elongation at break

mechanical parameters. In the case of MWCNTs, besides a considerable increase in breaking force, there is recorded a decided increase in the elongation at break, which directly indicates a considerable increase in the rigidity of material expressed with Young modulus.

\section{Conclusions}

The use of graphene or carbon nanotubes as effective flame-retardant agents for elastomeric nanocomposites depends to a large extent on the degree of their dispersion in the polymeric matrix. 
The addition of graphene or MWCNTs does not change the character of thermal processes of cross-linked ACR or SBR, but it causes a distinct increase in their thermal stability determined by parameters $T_{5}$ and $T_{50}$.

The increase in the activation energy of destruction and decrease in the value of parameter of elastomeric nanocomposites, in relation to unfilled vulcanizates, indicates that both graphene and CNTs inhibit free radical reactions, increasing at the same time the probability of the primary macro-radical recombination through the prolongation of their dwell time in the cage.

The increase in the thermal stability of the nanocomposites investigated under the influence of the nanoadditives incorporated is accompanied by a reduction in their flammability.

The presence of graphene as well as CNTs distinctly increases the value of parameter $P w$, both in the case of the nanocomposites of ACR and SBR, which causes that the quantity of flammable and nonflammable products of destruction passing to flame is lower.

Carbon fillers, well dispersed in the elastomer matrix, protect the polymer against the external flux of thermal radiation. The homogeneous carbon layer formed on the sample surface under combustion acts as a thermal shield reflecting heat radiation and consequently inhibiting the degradation and destruction of the polymer.

The nanoadditives used distinctly improve the mechanical properties of nanocomposites containing them.

Open Access This article is distributed under the terms of the Creative Commons Attribution 4.0 International License (http://creative commons.org/licenses/by/4.0/), which permits unrestricted use, distribution, and reproduction in any medium, provided you give appropriate credit to the original author(s) and the source, provide a link to the Creative Commons license, and indicate if changes were made.

\section{References}

1. Rybiński P, Janowska G, Dobrzyńska R, Kucharska A. Effect of halogenless flame retardants on the thermal properties, flammability and fire hazard of cross-linked EVA/NBR rubber blends. J Therm Anal Calorim. 2014;115:771-82.

2. Rybiński P, Janowska G, Jóźwiak M, Pająk A. Thermal stability and flammability of butadiene-styrene rubber nanocomposites. J Therm Anal Calorim. 2012;109:561-71.

3. Cerin O, Fontaine G, Duquesne S, Bourbigot S. Thermally stable and flame retardant elastomeric nanocomposites. In: Mittal V, et al., editors. Recent Adv Elastom Nanocompos. doi:10.1007/ 978-3-642-15787-5_6.

4. Ma P-C, Siddiqui NA, Marom G, Kim J-K. Dispersion and functionalization of carbon nanotubes for polymer-based nanocomposites: a review. Compos A. 2010;41:1345-67.

5. Uchida T, Kumar S. Single wall carbon nanotube dispersion and exfoliation in polymers. J Appl Polym Sci. 2005;98:985-9.

6. Topas K, Saswata B, Anata-Kumar M, Partha K, Nam Hoon K, Joang Hee L. Chemical functionalization of graphene and it applications. Prog Mater Sci. 2012;57:1061-105.
7. Novoselov KS, Geim AK, Morozow SV, Jiang D, Zhang Y, Dubanos SV, et al. Electric field effect in atomically thin carbon films. Science. 2004;306:666-9.

8. Shao Y, Wang J, Wu H, Liu J, Aksay IA, Lin Y. Graphene based electrochemical sensor and biosensors: a review. Electroanalysis. 2011;472:74-8.

9. Wu J, Becerril HA, Bao Z, Liu Z, Lhen Y, Peumans P. Organic solar cells with solution-processed graphene transparent electrodes. Appl Phys Lett. 2008;92:263302-4.

10. Huang J, Wang X, de Mello AJ, Bradley DDC. Efficient flexible polymer light emitting diodes with conducting polymer anodes. J Mater Chem. 2007;17:3551-4.

11. Park H, Rowehl JA, Kim KK, Bulovic V, Kong J. Doped graphene electrodes for organic solar cells. Nanotechnology. 2010;21:505204

12. Fang M, Wang K, Lu H, Yang Y, Nutt S. Covalent polymer functionalization of graphenenanosheets and mechanical properties of composites. J Mater Chem. 2009;19:7098-105.

13. Pingan S, Zhenhu C, Yuanzheng C, Liping Z, Zhengping F, Fu S. Fabrication of exfoliated graphene-based polypropylene nanocomposites with enhanced mechanical and thermal properties. Polymer. 2011;52:4001-10.

14. Li H, Siduo W, Jinrong W, Guangsu H. Enhanced electrical conductivity and mechanical property of SBS/graphene nanocomposites. J Polym Res. 2014;21:456-64.

15. Kuila T, Khanra P, Mishra AK, Kim NH, Lee JH. Functionalized graphene/ethylene vinyl acetate co-polymer composites for improved mechanical and thermal properties. Polym Test. 2012;31:282-9.

16. Stankovich S, Dikin DA, Dommett GHB, Kohlhaas KM, Zimney EJ, Stach EA, Piner RD, Nguyen ST, Ruoff RS. Graphene based composite materials. Nature. 2006;442:282-6.

17. Kuila T, Bose S, Hong CE, Uddin ME, Khanra P, Kim NH, Lee $\mathrm{JH}$. Preparation of functionalized graphene/linear low density polyethylene composites by solution mixing method. Carbon. 2011;49(3):1033-7.

18. Li D, Muller MB, Gijle S, Kaner RB, Wallace GG. Processable aqueous dispersions of graphene nanosheets. Nat Nanotechnol. 2008;3:101-5.

19. Kim KS, Zhao Y, Jang H, Lee SY, Kim JM, Kim KS, Ahn JH, Kim P, Choi JY, Hong BH. Large-scale pattern growth of graphene films for stretchable transparent electrodes. Nature. 2009;457:706-10.

20. Hsia B, Ferralis N, Senesky DG, Pisano AP, Carraro C, Maboudian R. Epitaxial graphene growth on 3C-SiC(111)/ $\operatorname{AIN}(0001) / \mathrm{Si}(100)$. Electrochem Solid-State Lett. 2011;14(2): $\mathrm{k} 13-5$.

21. Sun Z, Yan Z, Yao J, Beitler E, Zhu Y, Tour JM. Growth of graphene from solid carbon sources. Nature. 2010;468:549-52.

22. Park S, Ruoff RS. Chemical methods for the production of graphene. Nat Nanotechnol. 2009;4:217-24.

23. Patole AS, Patole SP, Kang H, Yoo J-B, Kim T-H, Ahn J-H. A facile approach to the fabrication of graphene/polystyrene nanocomposite by in situ microemulsion polymerization. J Colloid Interface Sci. 2010;350:530-7.

24. Ramanathan T, Abdala AA, Stankovich S, Dikin DA, Herrera-Alonso $\mathrm{M}$, Piner $\mathrm{RD}$, et al. Functionalized graphene sheets for polymer nanocomposites. Nat Nanotechnol. 2008;3(6):327-31.

25. Liang J, Huang Y, Zhang L, Wang Y, Ma Y, Guo T, et al. Molecular level dispersion of graphene into poly(vinyl alcohol) and effective reinforcement of their nanocomposites. Adv Funct Mater. 2009;19(14):2297-303.

26. Kim H, Macosko CW. Morphology and properties of polyester/ exfoliated graphite nanocomposites. Macromolecules. 2008; 41(9):3317-27. 
27. Yadav SK, Cho JW. Functionalized graphene nanoplatelets for enhanced mechanical and thermal properties of polyurethane nanocomposites. Appl Surf Sci. 2013;266:360-70.

28. Zhang LB, Wang JQ, Wang HG, Xu Y, Wang ZF, Li ZP, et al. Preparation, mechanical and thermal properties of functionalized graphene/polyimide nanocomposites. Compos Part A. 2012; 43(9):1537-45.

29. An JE, Jeon GW, Jeong YG. Preparation and properties for polypropylene nanocomposites reinforced with exfoliated graphene. Fibers Polym. 2012;13(4):507-14.

30. Bora C, Gogoi P, Baglari S, Dolui SK. Preparation of polyester resin/graphene oxide nanocomposite with improved mechanical strength. J Appl Polym Sci. 2013;129(6):3432-8.

31. Horcas I, Fernandez R, Gomez-Rodriguez JM, Colchero J, Gomez-Herrero J, Baro AM. WSXM: a software for scanning probe microscopy and a tool for nanotechnology. Rev Sci Instrum. 2007;78:13705.

32. Sun JT, Huang YD, Gong GF, Cao HL. Thermal degradation kinetics of poly(methylphenylsiloxane) containing methacryloyl groups. Polym Degrad Stab. 2006;91:339-46.

33. Rybiński P, Żukowski W, Bradło D. Influence of cenosphere particles on thermal properties composites of silicon rubber. J Therm Anal Calorim. 2015;122:1307-18.

34. Ozawa T. A new method of analyzing thermogravimetric data. Bull Chem Soc Jpn. 1965;38:1881-6.

35. Flyn JH, Wall LA. A quick direct method for determination of activation energy from thermogravimetric data. J Polym Sci Polym Lett. 1966;4:323-8.

36. Pająk A, Rybiński P, Janowska G, Kucharska-Jastrząbek A. The thermal properties and the flammability of pigmented elastomeric materials. J Therm Anal Calorim. 2014;117:789-98.
37. Hummers WS, Offeman RE. Preparation of graphite oxide. J Am Chem Soc. 1958;80:1339.

38. Rahmat M, Hubert P. Carbon nanotube-polymer interaction in nanocomposites: a review. Compos Sci Technol. 2011;72:72-84.

39. Rybiński P, Janowska G. Thermal properties and flammability of nanocomposites based on nitrile rubbers and activated halloysite nanotubes and carbon nanofibers. Thermochim Acta. 2012;549: $6-12$.

40. Wen X, Wang Y, Gong J, Liu J, Tian N, Wang Y, Jiang Z, Qiu J, Tany $\mathrm{T}$. Thermal and flammability properties of polypropylene/carbon black nanocomposites. Polym Degrad Stab. 2012;97: 793-801.

41. Kashiwagi T, Du F, Winey KI, Groth KM, Shields JR, Bellayer SP, Kim H, Douglas JF. Flammability properties of polymer nanocomposites with single-walled carbon nanotubes: effect of nanotube dispersion and concentration. Polymer. 2005;46: 471-81.

42. Balandin AA, Ghosh S, Bao W, Calizo I, Teweldebrhan D, Miao $\mathrm{F}$, et al. Superior thermal conductivity of single layer graphene. Nano Lett. 2008;8:902-7.

43. Ma P-Ch, Siddiqui NA, Marom G, Kim J-K. Dispersion and functionalization of carbon nanotubes for polymer-based nanocomposites: a review. Compos Part A. 2010;41:1345-67.

44. Dittrich B, Wartig K-A, Hofmann D, Mulhaupt R, Schartel B. Flame retardancy through carbon nanomaterials: carbon balck, multiwall nanotubes, expanded graphite, multi-layer graphene and graphene in polypropylene. Polym Degrad Stab. 2013;98: 1495-505. 